\title{
Damage control surgery in lung trauma
}

\section{Cirugía de control de daños del trauma pulmonar}

\author{
Alberto García ${ }^{1,2,3}$ Mauricio Millán ${ }^{3,4}$ Carlos A. Ordoñez $z^{1,2,3}$ Daniela Burbano ${ }^{5}{ }^{(® i c h a e l ~}$ \\ W. Parra ${ }^{6}$ Yaset Caicedo $^{(D)}$ Adolfo González Hadad ${ }^{1,8,9}{ }^{\circledR}$ Mario Alain Herrera ${ }^{1,8}$ Luis \\ Fernando Pino ${ }^{1,8}$ Fernando Rodríguez-Holguín ${ }^{(i D}$ Alexander Salcedo ${ }^{1,2,3,8}$ Maria Josefa \\ Franco $^{2}$ Ricardo Ferrada ${ }^{1,9}$ Juan Carlos Puyana ${ }^{10}$ \\ ordonezcarlosa@gmail.com, carlos.ordonez@fvl.org.co
}

1 Universidad del Valle, Facultad de Salud, Escuela de Medicina, Department of Surgery, Division of Trauma and Acute Care Surgery, Cali, Colombia. 2 Fundación Valle del Lili, Department of Surgery, Division of Trauma and Acute Care Surgery, Cali, Colombia. 3 Universidad Icesi, Cali, Colombia. 4 Fundación Valle del Lili, Department of Surgery, Division of Transplant Surgery, Cali, Colombia, 5 Fundación Valle del Lili, Departamento de Urgencias Adultos. Cali, Colombia. 6 Broward General Level I Trauma Center, Department of Trauma Critical Care, Fort Lauderdale , FL, USA, 7 Fundación Valle del Lili, Centro de Investigaciones Clínicas (CIC), Cali, Colombia, 8 Hospital Universitario del Valle, Department of Surgery, Division of Trauma and Acute Care Surgery, Cali, Colombia., 9 Centro Médico Imbanaco, Cali, Colombia., 10 University of Pittsburgh, Critical Care Medicine. Pittsburgh, PA, USA.

Citation: García A, Millán M, Ordoñez CA, Burbano D, Parra MW, Caicedo Y, González-Hadad A, Herrera MA, PINO LF, Rodríguez- Holguín F, Salcedo A, Franco MJ, Ferrada R, Puyana JC. Damage control surgery in lung trauma. Colomb Méd (Cali),

2021; 52(2):e4044683 http://doi. org/10.25100/cm.v52i 2.4683

Received : 04 Jan 2021

Revised: 15 Jan 2021

Accepted : 10 May 2021

Published: 11 May 2021

Keywords:

Damage control surgery; sternotomy; pneumonectomy; thoracotomy; chest tubes; hemothorax; lung injury; hemostatics; heart arrest; balloon occlusion; hemostasis; cardiac output

Palabras clave:

Cirugía de control de daños; esternotomía; neumonectomía; toracotomía; sondas torácicas; hemotórax; lesión pulmonar; hemostática; paro cardíaco; oclusión con balón; hemostasia; gasto cardíaco

Copyright: () 2021 Universidad del Valle (c) $(1)$

\section{Abstract}

Damage control techniques applied to the management of thoracic injuries have evolved over the last 15 years. Despite the limited number of publications, information is sufficient to scatter some fears and establish management principles. The severity of the anatomical injury justifies the procedure of damage control in only few selected cases. In most cases, the magnitude of the physiological derangement and the presence of other sources of bleeding within the thoracic cavity or in other body compartments constitutes the indication for the abbreviated procedure. The classification of lung injuries as peripheral, transfixing, and central or multiple, provides a guideline for the transient bleeding control and for the definitive management of the injury: pneumorraphy, wedge resection, tractotomy or anatomical resection, respectively.

Identification of specific patterns such as the need for resuscitative thoracotomy, or aortic occlusion, the existence of massive hemothorax, a central lung injury, a tracheobronchial injury, a major vascular injury, multiple bleeding sites as well as the recognition of hypothermia, acidosis or coagulopathy, constitute the indication for a damage control thoracotomy. In these cases, the surgeon executes an abbreviated procedure with packing of the bleeding surfaces, primary management with packing of some selected peripheral or transfixing lung injuries, and the postponement of lung resection, clamping of the pulmonary hilum in the most selective way possible. The abbreviation of the thoracotomy closure is achieved by suturing the skin over the wound packed, or by installing a vacuum system. The management of the patient in the intensive care unit will allow identification of those who require urgent reintervention and the correction of the physiological derangement in the remaining patients for their scheduled reintervention and definitive management. 
Conflicts of interest:

The authors declare that they have no conflict of interest.

Corresponding author:

Carlos A. Ordonez, MD, FACS. Division of Trauma and Acute Care Surgery, Department of Surgery. Fundación Valle del Lili. Cali, Colombia; Division of Trauma and Acute Care Surgery, Department of Surgery, Universidad del Valle, Cali, Colombia; Universidad Icesi, Cali, Colombia. e-mail: ordonezcarlosa@gmail.com, carlos.ordonez@fvl.org.co

\section{Resumen}

Las técnicas de control de daños aplicadas al manejo de lesiones torácicas han evolucionado en los últimos 15 años. A pesar de que el número de publicaciones es limitado, la información es suficiente para desvirtuar algunos temores y establecer los principios de manejo. La severidad del compromiso anatómico justifica el procedimiento de control de daños solamente en algunos casos. En la mayoría, la magnitud del deterioro fisiológico y la presencia de otras fuentes de sangrado dentro del tórax o en otros compartimientos corporales constituyen la indicación del procedimiento abreviado. La clasificación de la lesión pulmonar como periférica, transfixiante y central o múltiple, proporciona una pauta para el control transitorio del sangrado y para el manejo definitivo de la lesión: neumorrafía, resección en cuña, tractotomía o resecciones anatómicas, respectivamente. La identificación de ciertos patrones como la necesidad de toracotomía de reanimación o de oclusión aórtica, la existencia de un hemotórax masivo, de una lesión pulmonar central, una lesión traqueobronquial o una lesión vascular mayor, así como el reconocimiento de hipotermia, acidosis o coagulopatía, constituyen la indicación de una toracotomía de control de daños. En estos casos,el cirujano concluye de manera abreviada los procedimientos con empaquetamiento de las superficies sangrantes, el manejo primario con empaquetamiento de algunas lesiones pulmonares periféricas o transfixiante seleccionadas y el aplazamiento de la resección pulmonar, pinzando el hilio de la manera más selectiva posible. La abreviación del cierre de la toracotomía se logra con la sutura de la piel sobre el empaquetamiento de la herida, o mediante la instalación de un sistema de presión negativa. El manejo del paciente en cuidados intensivos permitirá identificar aquellos que requieren reintervención urgente y corregir la alteración fisiológica de los restantes para su reoperación programada y manejo definitivo.

\section{Remark}

\section{1) Why was this study conducted?}

This paper presents the applications of damage control in the management of patients with lung trauma

\section{2) What were the most relevant results of the study?}

Identification of specific patterns and the recognition of hypothermia, acidosis or coagulopathy, constitute the indication for a damage control thoracotomy. In these cases, the surgeon executes an abbreviated procedure with packing of the bleeding surfaces, primary management with packing of some selected peripheral or transfixing lung injuries, and the postponement of lung resection, clamping of the pulmonary hilum in the most selective way possible. The abbreviation of the thoracotomy closure is achieved by suturing the skin over the wound packed, or by installing a vacuum system.

\section{3) What do these results contribute?}

The present article proposes an algorithm for the management of lung trauma, in which the decision point lays in characteristics of the injury, like the localization, whether it is peripheric, central or multiple, and in its hemodynamic status. Providing a practical approach regarding surgical management and when to decide to perform damage control surgery. 


\section{Introduction}

Surgical damage control techniques seek to minimize time and surgical magnitude in order to restore the initial physiological derangement, for a following definite surgery to complete the final repair. These techniques were initially described for the management of abdominal injuries ${ }^{1,2}$. Damage control surgery has been extended beyond the abdomen and to situations other than trauma, after it has demonstrated to increase probability of survival in physiologically exhausted patients with shock ${ }^{3}$.

This paper presents the applications of damage control in the management of patients with lung trauma. This article is a consensus that synthesizes the experience acquired during the last 30 years in trauma management, general surgery and critical care of the trauma and emergency surgery group (cirugía de Trauma y Emergencias-CTE) in Cali, Colombia, conformed by experts from the Hospital Universitario Fundación Valle del Lili and the Hospital Universitario del Valle "Evaristo García”, with the Universidad de Valle and Universidad Icesi, in collaboration with the Colombian Association of Surgery and the Pan-American Trauma Society, joined by international specialist from United States.

\section{Epidemiology}

Frequency of thoracic trauma is highly variable, depending on the reported setting (prehospital, hospital or post-mortem), trauma mechanism and reporting of all thoracic injuries or only the ones with severity criteria. The reported prevalence of lung trauma fluctuates between $5-78 \%$, with a median of $22 \%{ }^{4-8}$. The prevalence of thoracic injuries was higher in patients with penetrating thoracic trauma, compared to patients with blunt thoracic trauma and those patients who died ${ }^{4,5}$.

Most thoracic trauma cases are solved with minor procedures, and only a small proportion requires thoracotomy. Historically, the proportion of patients requiring a thoracotomy fluctuates between $15-25 \%$, being higher in penetrating trauma ${ }^{9-12}$.

Damage control surgery for the management of lung trauma has been reported by a limited number of authors, although in recent years the number of publications on the subject has increased. Vargo and Battistella ${ }^{13)}$ from Sacramento-United States, and García et al. from Cali-Colombia ${ }^{14}$, reported experiences prior to 2015 with a rate of less than $6 \%$ of patients with thoracotomy who have undergone damage control surgery. However, reports of the last five years showed a rate of $22 \%$ and $21 \%$, respectively ${ }^{12,15}$. Chica et al., reported that $42 \%$ of patients who returned to spontaneous circulation after an emergency thoracotomy were managed with damage control surgery ${ }^{16}$.

The lung is the most frequently compromised organ in patients requiring damage control thoracotomy. A sub-analysis of patients with thoracic trauma who underwent emergency thoracotomy in Cali-Colombia reported that $72 \%$ of patients managed by damage control thoracotomy presented lung trauma, compared to those who did not required damage control thoracotomy, only $56 \%$ presented with lung trauma ${ }^{16}$. Similar to the case series from Baltimore-United states, were $86 \%$ of patients who require damage control thoracotomy presented with lung injuries ${ }^{15}$.

The reported experience of managing lung damage control with anatomical lung resection is limited. Some case series have reported a pneumonectomy or lobectomy rate of 32\% O'Connor and 26\% Deane for Baltimore-United States ${ }^{13,15}$, 20\% García and 15\% Chica for Cali-Colombia ${ }^{14,16}$. This last group has reported a rate greater than $3 \%$ of patients with lung resections without the need damage control thoracotomy ${ }^{16}$. 
Table 1. Indications for damage control thoracotomy

Indications for damage control thoracotomy

Physiological parameters

Clinical parameters
Glasgow $<9$

Temperature $<35 \mathrm{C}$ at the beginning of surgery

Arterial $\mathrm{pH}<7.2$

Base deficit $>15 \mathrm{mmol} / \mathrm{L}$

Lactate $>5 \mathrm{mmol} / \mathrm{L}$

Need for resuscitative thoracotomy

Need for aortic occlusion

Massive hemothorax

Central lung injury

Mayor vascular injury

Tracheobronchial injury

Multiple bleeding sources

Clinical coagulopathy

\section{Indications}

Exsanguination that leads the patient to depletion of the physiological reserve is the primary condition in a patient with thoracic trauma who will benefit from the management damage control principles. There are no clearly defined criteria as indications for thoracic damage control. Traditionally, it has been established that the identification of the triad of death, or the recently proposed lethal diamond (hypothermia, acidosis, coagulopathy and hypocalcemia), allows to recognize the individual who requires a damage control procedure ${ }^{17-19}$.

Research aimed to identify variables associated with the risk of damage control thoracotomy have found that alterations in arterial $\mathrm{pH}$, lactate levels, base deficit, preoperative hypothermia ${ }^{15}$, preoperative neurological status with alteration of consciousness, magnitude of hemothorax, need of aortic occlusion, central lung injury, mayor vascular injury, tracheobronchial injury or multiple bleeding sites are associated with the decision of a damage control surgical strategy ${ }^{16}$. (Table 1 )

It should be borne in mind that that methods that seek for laboratory test alteration have the risk of delaying decision-making while waiting for results, in a context where every minute counts. Therefore, it is advised that in addition to the components of the triad of death, the identification of certain clinical patterns previously mentioned can aid in early recognition of the indication for damage control ${ }^{16-18}$.

\section{Initial approach and diagnosis}

Initial management should be directed towards hemodynamic stabilization according to the ATLS (Advanced Trauma Life Support) guidelines and the principles of damage control resuscitation. Upon arrival of a patient with a penetrating thoracic injury, it must be determined

Table 2. Lung injury classification from the AAST

\begin{tabular}{cll}
\hline Grade* & Injury type & Description \\
\hline I & Contusion & Unilateral, <1 lobe \\
II & Contusion & Unilateral, single lobe \\
& Laceration & Simple pneumothorax \\
III & Contusion & Unilateral, $>1$ lobe \\
& Laceration & Persistent $(>72 \mathrm{~h}$ ) air leak from distal airway \\
& Hematoma & Nonexpanding intraparenchymal \\
IV & Laceration & Major (segmental or lobar) air leak \\
& Hematoma & Expanding intraparenchymal \\
& Vascular & Primary branch intrapulmonary vessel disruption \\
V & Vascular & Hilar vessel disruption \\
VI & Vascular & Total uncontained transection of pulmonary hilum \\
\hline *Advance one grade for bilateral injuries up to grade III. Hemothorax is scored under thoracic vascular injury scale
\end{tabular}




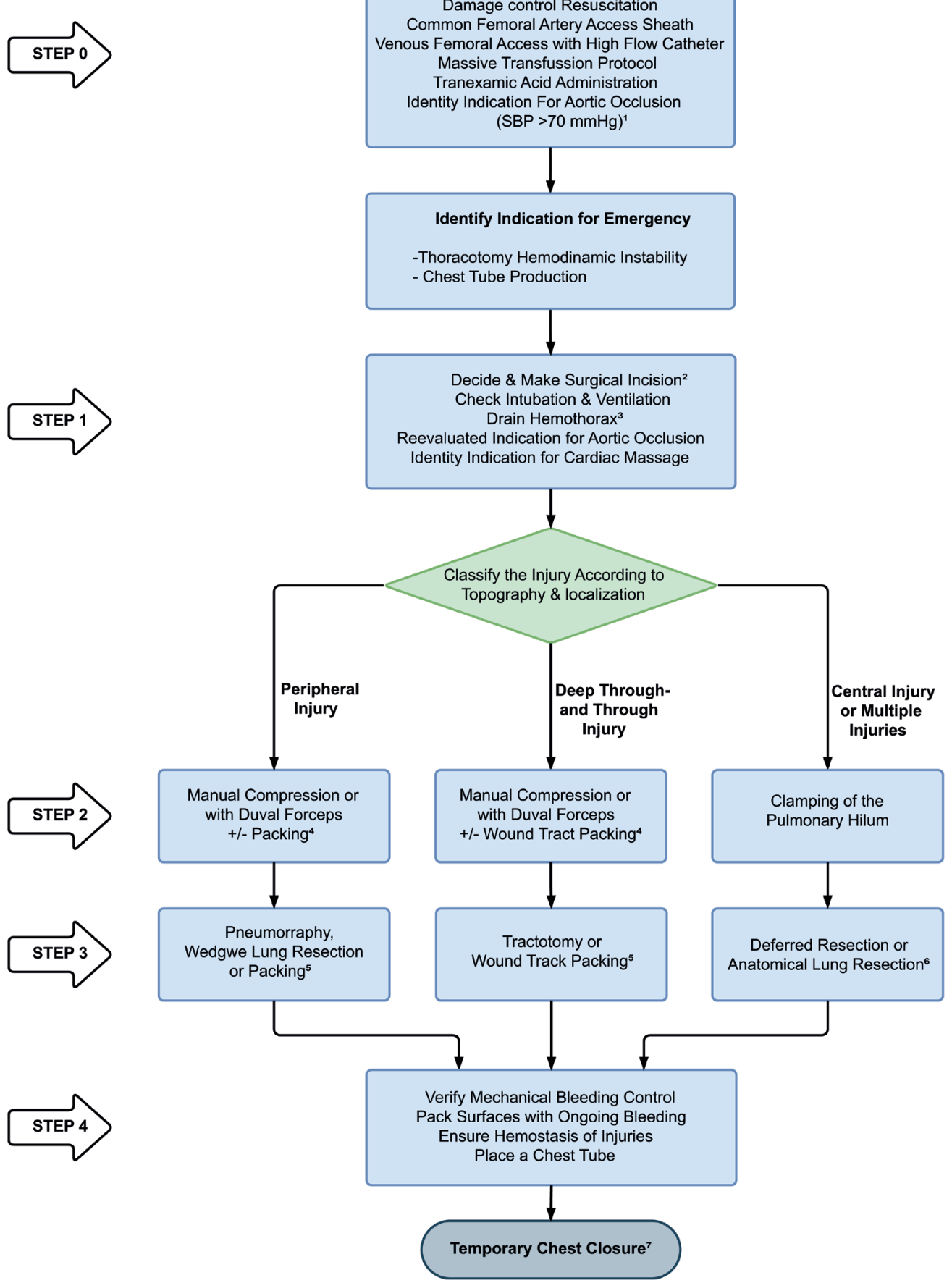

Severe Pulmonary Trauma

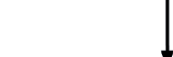

$A B C D E$

Massive Transfussion Protocol

Tranexamic Acid Administration

$(\mathrm{SBP}>70 \mathrm{mmHg})^{1}$

dentify Indication for Emergency

-Thoracotomy Hemodinamic Instability

Chest Tube Production

Decide \& Make Surgical Incision ${ }^{2}$

heck Intubation \& Ventilation

dentity Indication for Cardiac Massage

Figure 1. Algorithm for Surgical Management of Lung Trauma. Anotations: 1. Aortic occlusion can be made during the preoperative phrase by an endovascular balloon occlusion (REBOA). If the device or the protocols are not available, a left thoracotomy for aortic-cross clamping is indicated. 2. If a resuscitative thoracotomy is required, a left anterolateral incision must be performed. A sternotomy is indicated in central wounds. 3. Consider autotransfusion. 4. Packing around a peripheral injury or packing of a through-and-through wound should only be considered in patients with other more complex injuries requiring surgical team's attention. 5. Packing lung wound should be only deemed the definitive method only in complicated cases with exhausted physiologic reserve and hemorrhage control. 6. Anatomi resection in the index operation is recommended only if hemorrhe control is immediate and physiologic is almost completely restored. 7. Temporary chest closing can be achieved by packing the wound and suturing the skin over the pads or by a vacuum system. 
whether it warrants immediate surgical exploration or additional imaging studies, depending on its hemodynamic status. If the hemodynamic condition is stable, imaging methods such as FAST ultrasound, chest X-ray or chest CT are adequate to assess periclavicular, transmediastinal o thoracoabdominal injuries ${ }^{11}$.

Lung trauma is commonly classified according to the American Association for the Surgery of Trauma (AAST) classification. Nevertheless, this classification has a limited value in defining surgical treatment (Table 2).

The present article proposes an algorithm for the management of lung trauma, in which the decision point lays in characteristics of the injury, like the localization, whether it is peripheric, central or multiple, and in its hemodynamic status. Providing a practical approach regarding surgical management and when to decide to perform damage control surgery (Figure 1).

\section{Surgical approach}

Step 0: Profound preoperative hypotension (systolic arterial blood pressure $<70 \mathrm{mmHg}$ ) constitutes an indication for therapeutic aortic occlusion to provide hemodynamic support ${ }^{20}$. This can be achieved through an emergency thoracotomy to perform an aortic cross-clamping or with the placement of a REBOA (Resuscitative endovascular balloon occlusion of the aorta) in zone $\mathrm{I}^{21}$, this last one, especially when the aorta is not easily accessible, for example when performing a right thoracotomy ${ }^{22}$.

The placement of a REBOA, ideally, should be managed by the articulation of two surgical teams, while one is performing the endovascular procedure the other one is performing the main surgical approach. Additionally, the massive transfusion protocol must be activated, along with the administration of tranexamic acid. However, none of these actions should delay the immediate surgical intervention.

Step 1: Access to the thoracic cavity depends on the surgeon's experience and the thoracic area where the injury is suspected. The topographic localization of the injury and the identification of massive hemothorax detected through imaging studies or drainage through a chest-tube guides the decision. The most common reported surgical approaches are the left or right anterolateral thoracotomy. An incision is made in the fourth or fifth intercostal space up to the midaxillary line, and if further surgical exposure is needed, an extension of the surgical incision can be made to the contralateral side of the chest, in a Clamshell incision ${ }^{12-14}$.

Median sternotomy is a surgical approach that allows for a better cardiac and great vessel visualization, and if further surgical exposure is needed, an extension of the surgical incision can be made with a cervicotomy or supraclavicular incision ${ }^{12-14}$. However, its execution usually requires an extended surgical time, therefore it must be performed in specific situations, by trained and experienced surgeons counting with the accessibility to surgical instruments for its rapid execution.

Upon entering the thoracic cavity, the surgeon must:

a. Confirm correct intubation: verify lung expansion

b. Evacuate of the hemothorax: introducing suction into the cavity

c. Identify the possible source of massive bleeding: packing of the posterior and anterior region must be performed using the minimum number of lap sponges to have a better visualization of the surgical field when controlling the bleeding.

After these initial maneuvers, the surgeon must reevaluate the patient's hemodynamic status, if hypotension persists, descending aortic occlusion is required. Digital occlusion can be performed if hypotension is present and the sources of bleeding are easily controlled. However, if profound hypotension or bradycardia are present, or the need to perform advance maneuvers for bleeding control are required in different organs, aortic cross-clamping is indicated ${ }^{23}$. 
If an associated cardiac injury is suspected, a diagnostic pericardial window should be performed. In case of cardiac arrest or ineffective cardiac activity, cardiac massage should be performed ${ }^{23}$.

Step 2: transient bleeding control. Injury to most thoracic structures can cause considerable blood loss in a short time. The surgeon must be able to execute rapid and effective maneuvers for bleeding control, causing the least possible additional trauma, simultaneously to the damage control resuscitation.

Transient bleeding control of lung hemorrhage depends on the localization of the lesion, which can be central, peripheral, or multiple injuries.

Peripheral injuries: bleeding control can be achieved by manual compression of the tissue or by the placing a Duval forceps ${ }^{14,24}$ (Figure 2). Transient bleeding control of small injuries can be achieved by the placement of one or two lap sponges between the thoracic wall and the lung parenchyma ${ }^{18,24-26}$. Transient bleeding control of a transfixing lung injury can be achieved by manual compression of the tissue, by the placement of Duval forceps or by the insertion of a lap sponge through the wound (Figure 3$)^{24}$. These procedures should be performed in hemodynamically unstable patients, with multiple bleeding sites and possibly damage control candidates. When performing thoracic packing, attention must be taken to avoid compressing the heart or mediastinal shifting, which can affect diastolic filling with a decrease in cardiac output ${ }^{27}$.

Central or multiple injuries: clamping of the pulmonary hilum must be performed using a vascular clamp (Figure 4) ${ }^{14,24,28,29}$. Clamping is achieved by advancing the surgeons' left hand between the heart and the lung, sliding the palm over the lung surface until reaching and embracing the hilum with the index and middle fingers for a posterior occlusion of the hilum with a vascular clamp. Another reported technique is the pulmonary hilum twist in an emergency room thoracotomy ${ }^{30}$.

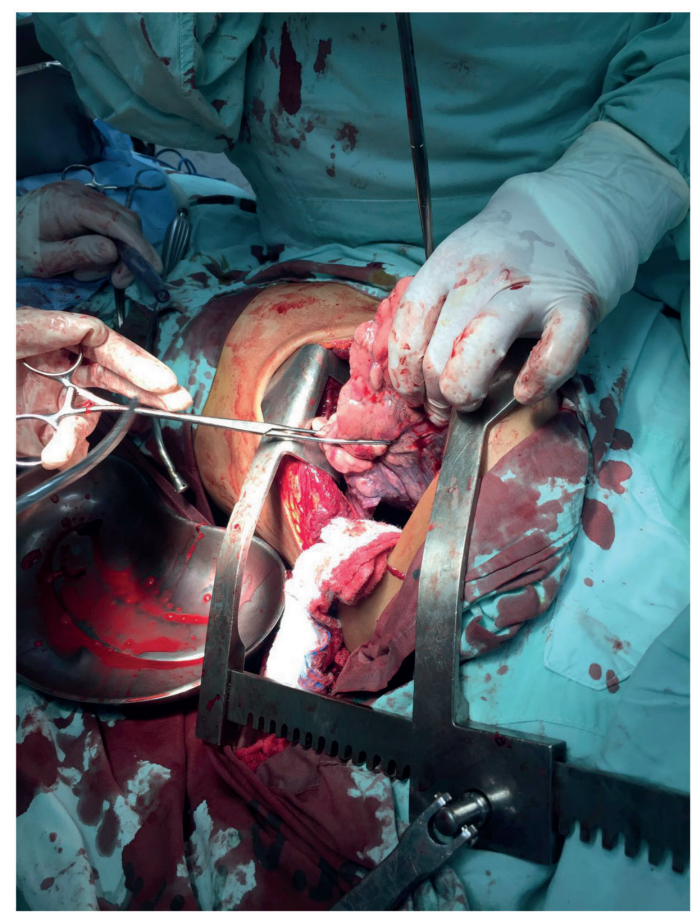

Figure 2. Transient hemorrhage control for peripheral injuries. Direct pressure with the surgeon's hand or a Duvall clamp frequently stops the hemorrhage transiently in a peripheral parenchymal wound. 
Step 3: Wound control. After bleeding control is achieved, management of the lung injury should be performed using conventional or damage control techniques. Localization of the wound must be determined if it is peripheral or central, single or multiple.

Tractotomy has being reported between $9-44 \%$ in patients with lung trauma and damage control surgery ${ }^{13,14}$. This technique allows control of peripheral and transfixing wounds in an expeditious manner while preserving lung tissue. This technique must be carried out by opening the wound tract, taking the lung tissue with atraumatic forceps (intestinal or aortic Crawford clamps) and making a manual cutting of the tissue with surgical scissors (31), or by mechanical linear stapler GIA 60-80 32 (Figure 5). Once the tract has been opened, the surgeon must identify bleeding sites and air leaks, then ligate them with a cross-stitch (in X) of polypropylene $3-0$ or $4-0^{31,32}$. If the wound tract has been open by cutting the lung tissue between atraumatic clamps, a continuous horizontal mattress hemostatic suture should be performed, with stitches below the clamps along the cross section ${ }^{31}$ (Figure 5). Frequently, a second line of running suture is necessary to achieve complete hemostasis. However, it is recommended to open the wound tract with one or two shots of linear stapler, which saves time and minimizes additional lung trauma. In coagulopathic patients, one or two lap sponges should be placed on the lung surface, since superficial bleeding may be present ${ }^{14}$.

Performing a tractotomy is no synonym of damage control surgery. The decision to determine if the patient can be managed definitely in the first surgery or if an abbreviated approach is required, is determined by the analysis of the physiological state, concomitant injuries and the need to perform additional procedures of greater technical skill.

The management of patients requiring emergency thoracotomy performed in Cali-Colombia were reported by Chica et $\mathrm{al}^{(16)}$. The characteristics and clinical results are described in Table 3 .
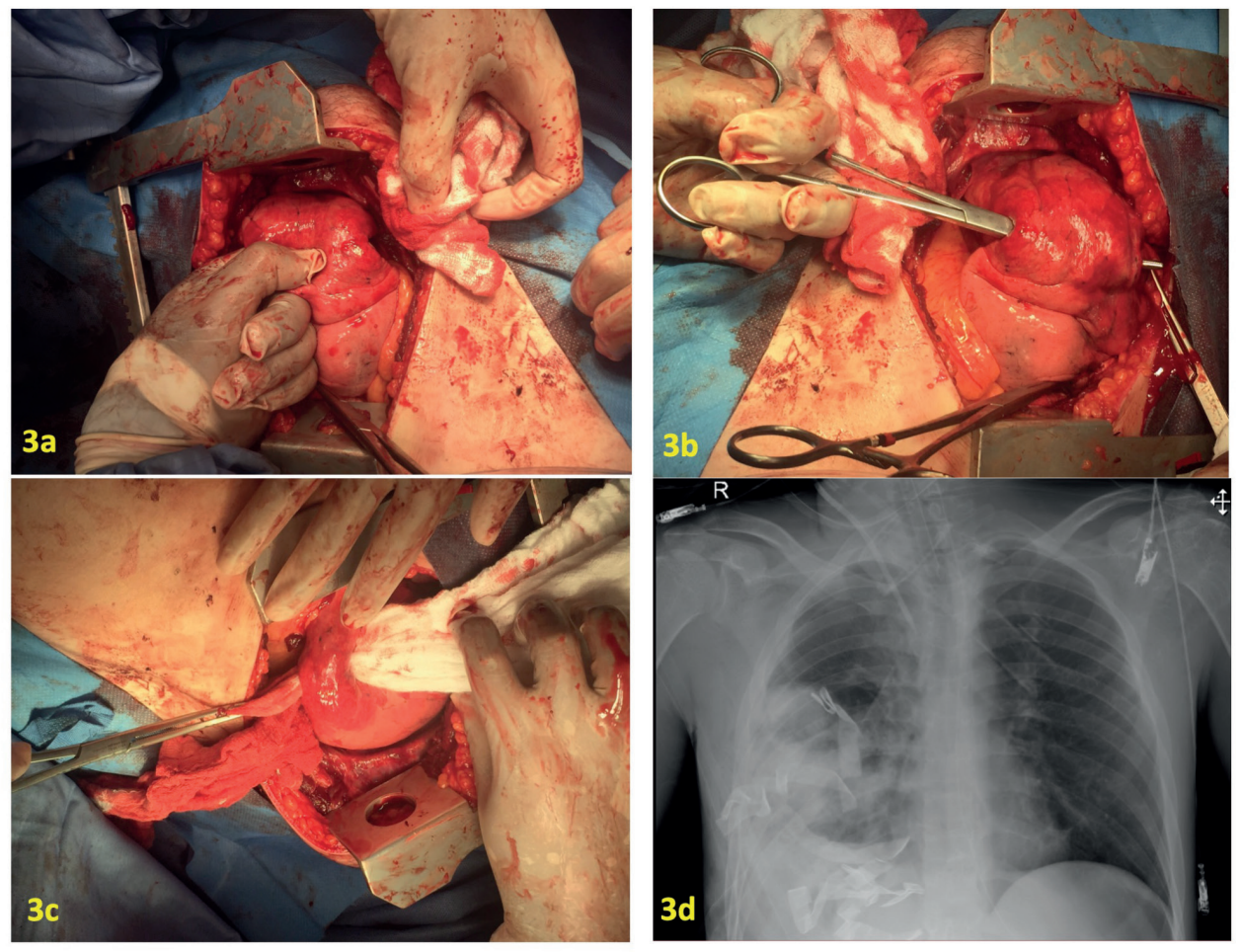

Figure 3. Packing of the tract in a through-and- through peripheral lung wound. a) The surgeon introduces a finger gently in the tract, exploring it, and preparing to guide a hemostatic clamp. B) The hemostatic clamp has been introduced in the wound guided by the surgeon's finger. C) The surgeon exerts traction with a laparotomy pad driving it into the wound, and gently adapting it to the wound shape. D) A Postoperative Chest X-Ray obtained immediately post procedure depicts, the intraparenchymal packing filling the lower part of the thorax, permitting the lung expansion without mediastinal deviation. 


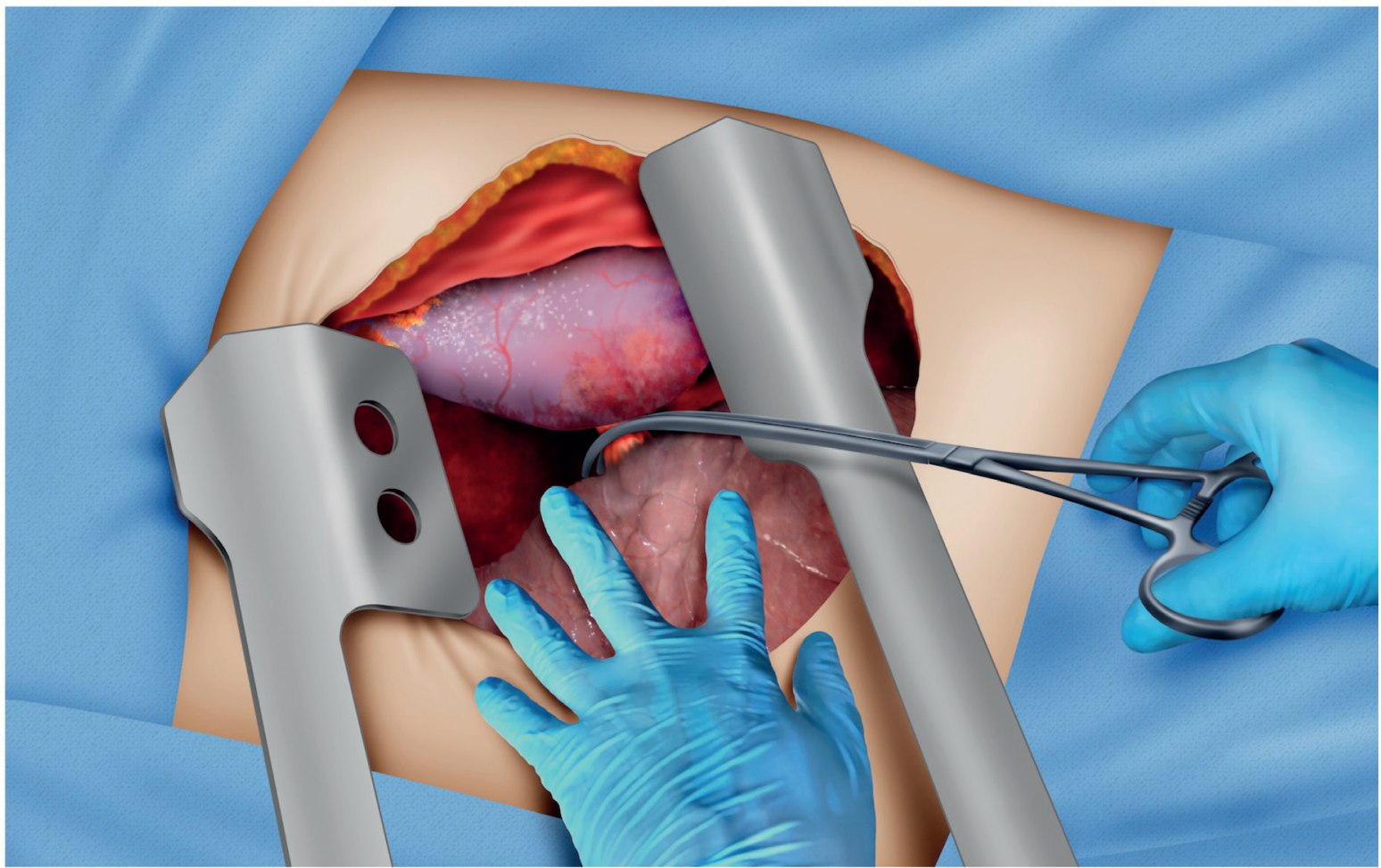

Figure 4. Cross clamping of the lung hilum. This patient has multiple exsanguinating lung wounds. The surgeon's left hand is introduced between the lung and the heart, making room for the clamp application. The index and middle fingers embrace the hilum to make facilitate the placement of the atraumatic clamp.
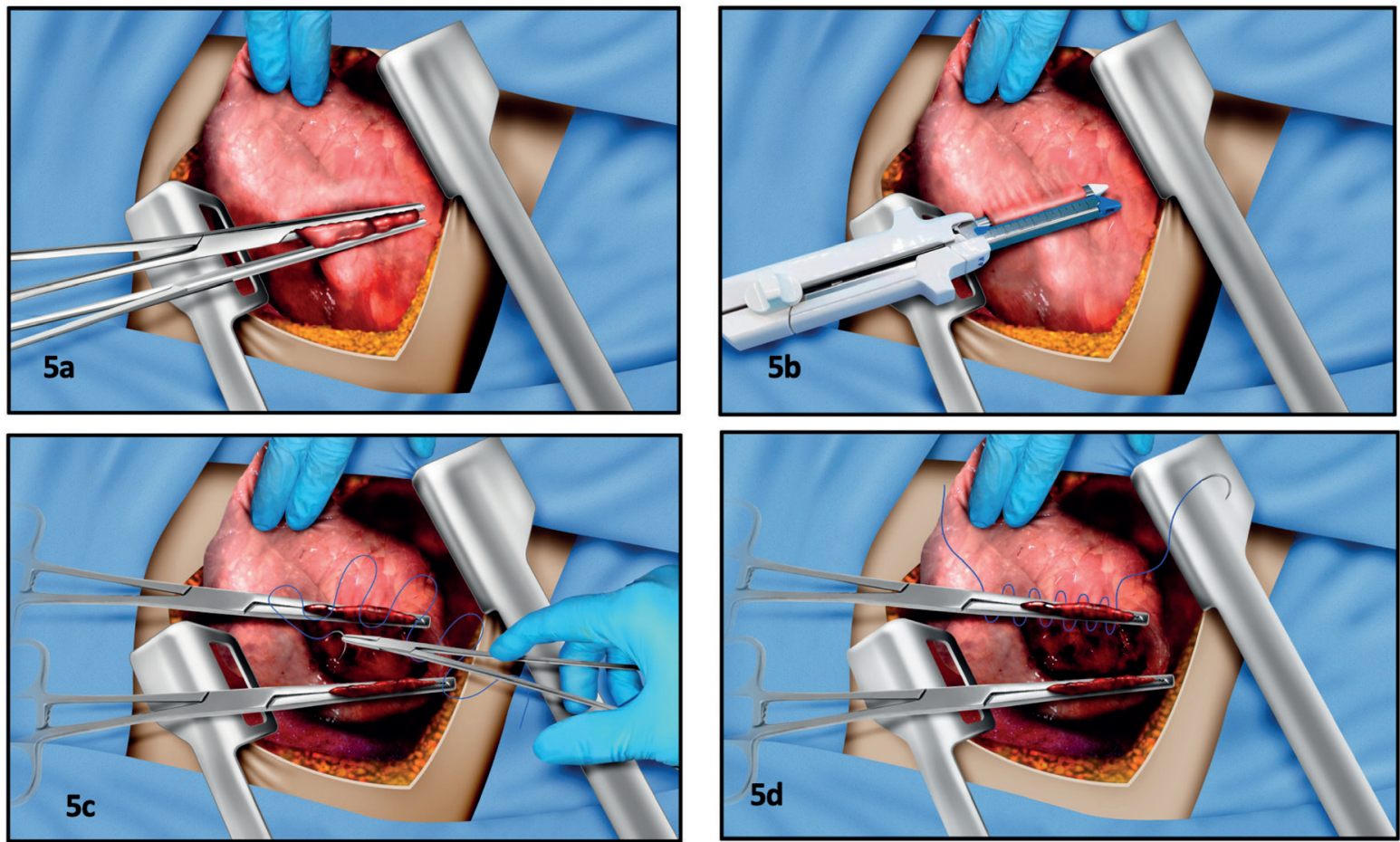

Figure 5. Pulmonary tractotomy. A) Two atraumatic clamps take the bridge of tissue across the tract created by the penetrating injury. The tissue is cut with a scalpel or a scissor, exposing the interior of the wound. B) The surgeon can drive the linear staple along opening of the tract, thus reducing surgical trauma, saving time, and avoiding blood loss. C) After exposing the inner aspect of the wound, the bleeding vessels and the air leaks are selectively ligated with 3/0 monofilament in figure of "8" stitches. D) If the tract was opened with clamps and scissors or scalpel, the tissue beneath the clamps must be oversewn with a monofilament 3-0 suture. Occasionally a second suture line must be performed to achieve the hemostasis, as is shown in the figure. 
Table 3. Management characteristics and clinical results of patients with emergent thoracotomy with and without damage control surgery.

\begin{tabular}{|c|c|c|}
\hline Variable & Damage control surgery $(n=53)$ & Initial definitive surgical management $(n=63)$ \\
\hline Resuscitative thoracotomy, n (\%) & $14(26.4)$ & $4(6.4)$ \\
\hline Aortic clamping, n (\%) & $18(34.0)$ & $5(7.9)$ \\
\hline Lung trauma, n (\%) & $38(71.7)$ & 35 (55.6) \\
\hline Pneumorrhaphy, n (\%) & $12(22.6)$ & $9(14.3)$ \\
\hline Tractotomy, n (\%) & $16(30.2)$ & $16(25.4)$ \\
\hline Lung resection, n (\%) & $8(15.1)$ & $2(3.2)$ \\
\hline \multicolumn{3}{|l|}{ Lung packing } \\
\hline Primary method, n (\%) & $9(17.0)$ & -- \\
\hline Complementary method, n (\%) & $14(26.4)$ & -- \\
\hline Clamping of the pulmonary hilum, (n\%) & $10(18.9)$ & $4(6.3)$ \\
\hline Vascular trauma, n (\%) & $25(47.2)$ & $18(28.6)$ \\
\hline Intercostals or internal thoracic minor vessels, $\mathrm{n}(\%)$ & $17(32.1)$ & $16(25.4)$ \\
\hline Mayor vascular injury & $8(15.1)$ & $1(1.6)$ \\
\hline Cardiac trauma, n (\%) & $9(17.0)$ & $26(41.3)$ \\
\hline Thoracic wall packing, n (\%) & $23(43.3)$ & -- \\
\hline Extrathoracic damage control, n (\%) & $24(45.8)$ & $9(14.3 \%)$ \\
\hline In-hospital mortality & $13(24.5)$ & $6(9.5)$ \\
\hline
\end{tabular}

Pneumorrhaphy or wedge lung resection with a linear stapler after clamping injured lung tissue with a Satinsky forceps is rarely used during a damage control thoracotomy ${ }^{14,15}$. Nevertheless, they can be suitable for definite management of small peripheral injuries in patients with multiple bleeding sites.

In central or multiple injuries patients are candidates for an anatomical lung resection (pneumonectomy or lobectomy). These procedures are associated with a high mortality rate, that has not changed in the last 45 years ${ }^{33}$. It is higher in patients with blunt trauma, and it increases as the extent of resection is greater ${ }^{32,34,35}$. Due to the exsanguinating nature of central lesions, these patients are candidates for a damage control procedure. Authors have proposed transient clamping of the lung hilum to allow postponement of lung resection, once coagulopathy, hypothermia, and hypoperfusion have been reversed ${ }^{14}$.

For this purpose, once bleeding control is achieved by clamping the lung hilum, the surgeon must evaluate the magnitude of the injury, and decide if it is a peripheric injury than can be managed by a wedge lung resection or a tractotomy. If it is a central injury that warrants resection ${ }^{18}$, it must be evaluated if it is possible to selectively occlude the circulation of the injured lobe or if the hilum needs to stay clamped ${ }^{14}$. Unless the patient has stabilized and a definitive hemodynamic stability is assured, it will be preferable to conclude the surgery with abbreviated maneuvers to allow resuscitation, and to perform the lobectomy or pneumonectomy in a semielective manner in a subsequent procedure, within the following 24 hours, in the company of a thoracic surgeon (Figure 6).

Step 4: After completing the damage control procedure, the surgeon should check the bleeding sites and confirm absence of active bleeding. If necessary, lap sponges must be replaced, ensuring hemostasis with the minimum number of them. It must be checked that the packing is not compressing the vena cava or the heart. Abbreviated closure of a thoracotomy or a sternotomy is achieved by installing a negative pressure system or by packing the muscular layer and closing the skin ${ }^{13,36,37}$. This last method is recommended by the authors, since it is a quick procedure to execute with a successful rate of bleeding control of the surgical wound. This technique must be performed by placing the lap sponges in the wound angles, especially in the area where blood is leaking through the thoracic wall, keeping them in place while the skin is being closed by a continuous suture, adjusting the lap sponge as the suture advances (Figure 7). The placement of a chest-tube is recommended to watch over thoracic bleeding. 

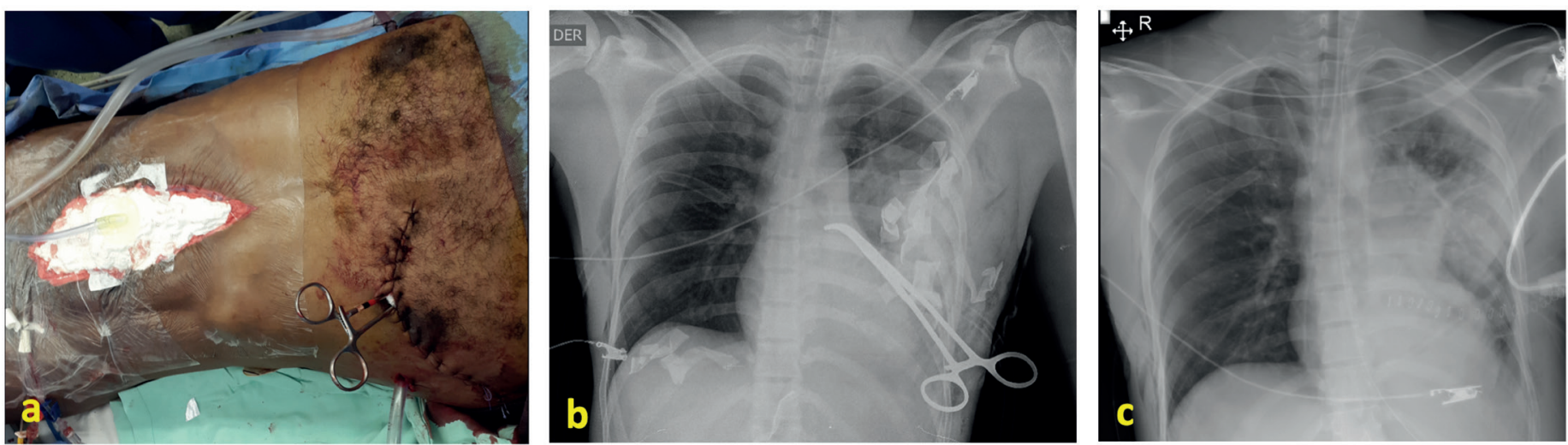

Figure 6. Clamping of the pulmonary hilum for a deferred anatomic resection. A) This patient was submitted to a resuscitative thoracotomy because of exsanguinating injuries in the lower left lobe, near the hilum, and the left hepatic lobe. He received open cardiac massage, aortic cross-clamping, and defibrillation (\#3). Hemorrhage was arrested by clamping the vascular structures of the inferior lobe of the left lung and by liver packing. The chest was closed by suturing the skin over pads and the abdomen with a vacuum system. B) Postoperative chest x-ray showing the left superior lobe completely expanded. The clamp occludes the inferior left lobe's vascular structures, and there are pads packed in the lower part of the chest and upper abdomen. C) Chest X-rays after the lobectomy, which was performed two days after the index surgery.
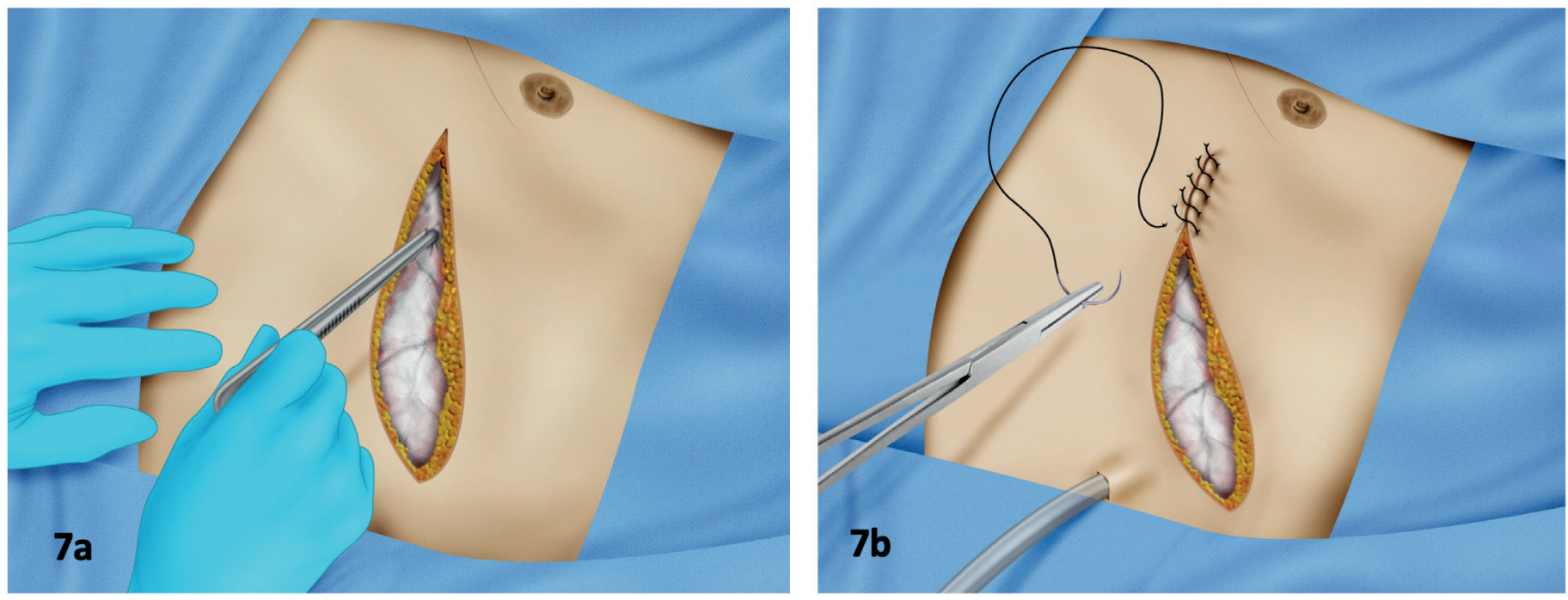

Figure 7. Packing and abbreviated closure of the thoracic wall. A) This technique expedites the closure of the thoracic incision. After checking for mechanical bleeding the surgeon places two or three laparotomy pads in the wound, between the muscular layers and the subcutaneous fat, packing the edges and by doing this, oozing around the edges of the wound is controlled. B) The skin is sutured over the pads, completing the packing effect.

\section{Prognosis}

Patients treated with damage control thoracotomy are at high risk of complications. The need for an emergency reintervention due to persistent bleeding occurs in $14-24 \%$ of cases ${ }^{13,14,26}$. Infectious complications such as pneumonia have been reported between $20-32 \%$, while empyema has a prevalence between $4-23 \%$. Organ dysfunction can occur in up to $88 \%$ of patients. Respiratory dysfunction has been reported between $25-84 \%$, cardiovascular between $41-76 \%$ and renal between $20-43 \%$. The requirement of renal-replacement therapy is present between $4-30 \%$ in patient with damage control thoracotomy (Table 4).

The in-hospital mortality associated with damage control surgery for lung trauma has been estimated at $28 \%$ according to a systematic review that grouped results from various case series ${ }^{18}$. It has been identified that the severity of the trauma (measured by the Injury Severity Score - ISS), the magnitude of the required lung resection, renal dysfunction, requirement of renal-replacement therapy, extracorporeal membrane oxygenation support (ECMO) and penetrating trauma are associated with higher mortality ${ }^{13,26}$. However, the experienced reported 
Table 4. Complications and intrahospital mortality before damage control thoracotomy

\begin{tabular}{|c|c|c|c|}
\hline Complication & O'Connor $(n=44)$ & Mackowski $(\mathrm{n}=25)$ & García $(n=25)$ \\
\hline Pneumonia (\%) & 27 & 32 & 20 \\
\hline Empyema (\%) & 23 & 4 & 16 \\
\hline Respiratory Dysfunction (\%) & $25^{*}$ & $36^{* *}$ & $84^{* * *}$ \\
\hline Cardiovascular Dysfunction (\%) & $41 \S$ & -- & 769 \\
\hline Renal Failure (\%) & 43 & -- & 20 \\
\hline Thoracic Compartment Syndrome (\%) & 2 & 0 & 4 \\
\hline Reintervention by bleeding (\%) & 14 & 0 & 24 \\
\hline Intrahospital Mortality (\%) & 23 & 40 & 24 \\
\hline
\end{tabular}

* Respiratory Distress Syndrome

${ }_{* *}^{*}$ Prolonged mechanical ventilation

$* * *$ More than 2 days of ventilatory support.

$\$$ Vasopressors support to discharge of surgery

g Vasoactive or inotropic drugs therapy

by Garcia et al. showed a higher survival rate in patients who required mayor lung resection (pneumonectomy or lobectomy), when the procedure was carried out in a subsequent surgery by leaving the lung hilum clamped in the first intervention, contrasting the experience reported by the case series from north America ${ }^{14}$.

Intuitively, the reduction of bleeding due to the early decision to intervene the patient, the prompt bleeding control, the early application of the principles of damage control, and the decision of performing an abbreviated procedure will improve the survival probability of patients with severe thoracic trauma with depletion of the physiological reserve.

\section{Discussion}

Damage control thoracotomy has evolved from tractotomy, designed to shorten the surgery, to a series of procedures that temporarily control the sources of bleeding, allowing a deferred management of the lung injury. This in order to increase survival of patient with depletion of the physiological reserve, allowing resuscitation and a subsequent definitive management. Indications and execution of damage control procedures are still a matter of debate and controversy. Literature is limited, and few groups worldwide have reported their experience.

Early identification of whether a patient benefits from damage control surgery, or not, enables activation of resuscitation protocols and redirects surgical effort towards a damage control thoracotomy. Two groups have researched the variables that differentiate patients who require thoracic damage control ${ }^{15,16}$. They have reported the following conditions that relates to a damage control approach: neurological status upon admission, resuscitative thoracotomy, need of a concomitant laparotomy, severe lung injury, mayor vascular injury, tracheobronchial injury, massive hemothorax, hypothermia, acidosis and coagulopathy.

Refractory hypotension (SBP $<70 \mathrm{~mm} \mathrm{Hg}$, despite resuscitation) in the preoperatory period or during surgery when there is no access to the aorta, such as a partial sternotomy or a right thoracotomy, are indications for an aortic occlusion by the positioning of a REBOA in zone I, procedure that should be carried out by a surgical team that works simultaneously with those who are performing the surgical approach for the management of the injuries ${ }^{20,21}$.

There is concern about increasing bleeding due to increased blood pressure. A recent study that included three porcine models of thoracic trauma (lung injury, thoracic venous injury or subclavian artery injury) revealed that the use of REBOA does not aggravate lung damage or increases exsanguination rate ${ }^{38}$.

Authors have provided clinical evidence on the use of REBOA in this group of patients: Ordoñez et al. reported 23 patients with thoracic trauma managed with REBOA. Eleven of them had lung injury and six had involvement of the lung hilum. The most common management was placement of the REBOA in zone I, with sternotomy in $65.2 \%$ of patients and 
Table 5. Comparison between emergency thoracotomy patients treated with or without damage control and thoracic packing.

\begin{tabular}{|c|c|c|}
\hline Variable & Damage control surgery $(n=53)$ & Initial definitive surgical management $(n=63)$ \\
\hline \multicolumn{3}{|l|}{ Respiratory parameters, first day post-trauma } \\
\hline FiO2, (median IQR) & $0.5(0.5-0.5)$ & $0.5(0.4-0.6)$ \\
\hline PO2/FiO2, (median IQR) & $332.8(155-3909$ & $262.9(173.3-413.2)$ \\
\hline Arterial pH, (median IQR) & $7.27(7.15-7.29)$ & $7.33(7.26-7.37)$ \\
\hline PCO2, (median IQR) & $41.6(36.8-44.5)$ & $36.3(32.3-42.5)^{\star}$ \\
\hline Base deficit mmol/L (median IQR) & $8(6-12.9)$ & $5.8(3.7-9.0)^{\star}$ \\
\hline Tidal volume ml, (median IQR) & $480(450-500)$ & $510(484-550)^{\star \star}$ \\
\hline Respiratory rate, breathings/min (median IQR) & $18(16-22)$ & $17(15-20)$ \\
\hline PEEP, $\mathrm{H} 2 \mathrm{O}$ cm (median IQR) & $5(5-8)$ & $5(5-6)$ \\
\hline Peak inspiratory pressure, $\mathrm{H} 2 \mathrm{O} \mathrm{cm}$ (median IQR) & $28(25-32)$ & $25(22-29)^{\star *}$ \\
\hline Dynamic compliance, (median IQR) & $21.5(19.2-25)$ & $25.2(22.7-31.9)^{\star \star}$ \\
\hline \multicolumn{3}{|l|}{ Clinical results } \\
\hline Days-off of Mechanical Ventilation, (median IQR) & $25(0-27)$ & $29(24-29)^{* * *}$ \\
\hline Patients with mechanical ventilation complications, n (\%) & $9(33.3)$ & $7(18.9)$ \\
\hline Atelectasis, $\mathrm{n}(\%)$ & $6(22.2)$ & $5(13.5)$ \\
\hline Pneumonia, n (\%) & $6(22.2)$ & $5(13.5)$ \\
\hline Pneumothorax, n (\%) & $0(--)$ & $3(8.1)$ \\
\hline Mortality, n (\%) & $7(25.9)$ & $5(13.5)$ \\
\hline
\end{tabular}

IQR interquartile range. PEEP Positive end expiratory pressure.

Wilcoxon-Mann-Whitney test ${ }^{*}<0.05^{* *}<0.01^{* * *}<0.001$

thoracotomy in $17.3 \%$. No significant differences were found between observed and expected mortality, nor higher requirement for blood components ${ }^{19}$. García et at. analyzed the impact of the REBOA on mortality in a group of patients with penetrating torso injury using a multivariate model. They found that the use of REBOA during surgery was associated with a better chance of survival ${ }^{21}$.

The need for a tractotomy does not necessarily implies damage control surgery. The decision to perform, or not, a damage control thoracotomy depends on the physiological derangement presented by the patient. In the series of patients undergoing emergency thoracotomy reported by Chica et al., $50 \%$ of the tractotomies were performed outside the context of damage control surgery ${ }^{16}$.

Packing is a technique that has been considered in thoracic damage control. Manzano et al. conducted a systematic review of the literature where they identified 14 studies ${ }^{14}$. Most of the publications described the use of the technique as a complement to other procedures in coagulopathic individuals. In some reports, packing is described as the primary technique for treating a lung injury. In most cases by placing lap sponges between the surface of the injured lung and the chest wall. The intrapulmonary packing technique ${ }^{24}$, was used in selected cases with various bleeding sources, some more complex, which required the attention of the surgical group.

Authors evaluated the impact of thoracic packing on mechanical ventilation. They found a reduction in dynamic compliance leading to a moderate decrease in tidal volume and moderate $\mathrm{CO} 2$ retention. Oxygenation was not compromised and in no case did the packaging induce critical difficulties for ventilatory support (Table 5) ${ }^{39}$.

Patients who require anatomical lung resection have a high risk of death, fluctuating between $50 \%$ and $100 \%$ in the different published series (31). The Trauma and Emergencies Surgery Group (Cirugía de Trauma y Emergencias - CTE) of Cali, has addressed this situation by occluding of the pulmonary hilum as selectively as possible, allowing resuscitation of the patient and the execution of pneumonectomy or lobectomy in a second stage. Five patients were managed in this way. Three patients underwent pneumonectomy and two lobectomy, only one case had a fatal outcome ${ }^{14}$.

The technique of temporary wall closure can be performed by installing a commercial or handcrafted vacuum system, or by packing the thoracic wall and rapid closure with a running suture ${ }^{13,14,37}$. There are no comparative studies, and both techniques seem to solve the need for rapid closure with control of thoracic wall bleeding. 


\section{Conclusion}

Hemodynamic instability and severe lung trauma are indications for damage control surgery. Transient pulmonary bleeding control can be achieved for peripheral wounds via local pressure maneuvers and central or multiples wounds perform a clamping of the pulmonary hilum. The pulmonary resection should be reserved as a deferred procedure after the hemodynamic resuscitation in the intensive care unit.

\section{References}

1. Stone HH, Strom PR, Mullins RJ. Management of the Major Coagulopathy with Onset during Laparotomy. Ann Surg. 1983;197:532-5. Doi: 10.1097/00000658-198305000-00005.

2. Rotondo MF, Schwab CW, McGonigal MD, Phillips GR, Fruchterman TM, Kauder DR, et al. 'Damage control': An approach for improved survival in exsanguinating penetrating abdominal injury. J Trauma. 1993;35:37583. Doi: 10.1097/00005373-199309000-00008.

3. Roberts DJ, Ball CG, Feliciano D V., Moore EE, Ivatury RR, Lucas CE, et al. History of the Innovation of Damage Control for Management of Trauma Patients: 1902-2016. Ann Surg. 2017;265:1034-44. Doi: 10.1097/ SLA.0000000000001803.

4. Zhao XG, Ma YF, Zhang M, Gan JX, Xu SW, Jiang GY. Comparison of the new injury severity score and the injury severity score in multiple trauma patients. Chinese J Traumatol. 2008;11:368-71. Doi: 10.1016/S10081275(08)60074-7.

5. Valdez C, Sarani B, Young H, Amdur R, Dunne J, Chawla LS. Timing of death after traumatic injury-a contemporary assessment of the temporal distribution of death. J Surg Res. 2016;200:604-9. Doi: 10.1016/j. jss.2015.08.031.

6. Gasparri M, Karmy-Jones R, Kralovich KA, Patton JH, Arbabi S. Pulmonary tractotomy versus lung resection: viable options in penetrating lung injury. J Trauma. 2001;51:1092-7. Doi: 10.1097/00005373-200112000-00013.

7. Byun CS, Park IH, Oh JH, Bae KS, Lee KH, Lee E. Epidemiology of trauma patients and analysis of 268 mortality cases: Trends of a single center in Korea. Yonsei Med J. 2015;56:220-6. Doi: 10.3349/ymj.2015.56.1.220.

8. Bayer J, Lefering R, Reinhardt S, Kühle J, Südkamp NP, Hammer T. Severity-dependent differences in early management of thoracic trauma in severely injured patients - Analysis based on the Trauma Register DGU ${ }^{\circledR}$. Scand J Trauma Resusc Emerg Med. 2017;25(1):10. Doi: 10.1186/s13049-017-0354-4.

9. O'Connor JV, Moran B, Galvagno SM, Deane M, Feliciano DV, Scalea TM. Admission Physiology vs Blood Pressure: Predicting the Need for Operating Room Thoracotomy after Penetrating Thoracic Trauma. J Am Coll Surg. 2020; 230(4):494-500. Doi: 10.1016/j.jamcollsurg.2019.12.019.

10. Cothren C, Moore EE, Biffl WL, Franciose RJ, Offner PJ, Burch JM. Lung-sparing techniques are associated with improved outcome compared with anatomic resection for severe lung injuries. J Trauma - Inj Infect Crit Care. 2002;53:483-7. Doi: 10.1097/00005373-200209000-00015.

11. Karmy-Jones R, Namias N, Coimbra R, Moore EE, Schreiber M, McIntyre R, et al. Western trauma association critical decisions in trauma: Penetrating chest trauma. J. Trauma Acute Care Surg. 2014;77(6):994-1002 doi: $10.1097 /$ TA.0000000000000426.

12. Orlas CP, Herrera-Escobar JP, Zogg CK, Serna JJ, Meléndez JJ, Gómez A, et al. Chest Trauma Outcomes: Public Versus Private Level I Trauma Centers. World J Surg. 2020; 44(6):1824-1834. Doi: 10.1007/s00268-02005400-w. 
13. Vargo DJ, Battistella FD. Abbreviated thoracotomy and temporary chest closure: An application of damage control after thoracic trauma. Arch Surg. 2001;136:21-4. Doi: 10.1001/archsurg.136.1.21.

14. Garcia A, Martinez J, Rodriguez J, Millan M, Valderrama G, Ordoñez C, et al. Damage-control techniques in the management of severe lung trauma. J Trauma Acute Care Surg. 2015;78:45-50. Doi: 10.1097/ TA.0000000000000482.

15. Deane M, Galvagno SM, Moran B, Stein DM, Scalea TM, O'Connor J V. Shock, Not Blood Pressure or Shock Index, Determines the Need for Thoracic Damage Control Following Penetrating Trauma. Shock. 2020;54:4-8. Doi: 10.1097/SHK.0000000000001472.

16. Chica J, Garcia A, Naranjo MP. Life saving surgical techniques for thoracic trauma: predictors for the need of damage control thoracotomy. Eur J Trauma Emerg Surg. 2018;44(Supl 2):441.

17. O'Connor J V., DuBose JJ, Scalea TM. Damage-control thoracic surgery: Management and outcomes. J Trauma Acute Care Surg. 2014;77:660-5. Doi: 10.1097/TA.0000000000000451.

18. Roberts DJ, Bobrovitz N, Zygun DA, Ball CG, Kirkpatrick AW, Faris PD, et al. Indications for use of damage control surgery in civilian trauma patients. A content analysis and expert appropriateness rating study. Ann Surg. 2016;263:1018-27. Doi: 10.1097/SLA.0000000000001347.

19. Manzano-Nunez R, Chica J, Gómez A, Naranjo MP, Chaves H, Muñoz LE, et al. The tenets of intrathoracic packing during damage control thoracic surgery for trauma patients: a systematic review. Eur J Trauma Emerg Surg. 2020; 47(2):423-434. Doi: 10.1007/s00068-020-01428-8.

20. Ditzel RM, Anderson JL, Eisenhart WJ, Rankin CJ, DeFeo DR, Oak S, et al. A review of transfusion- And trauma-induced hypocalcemia: Is it time to change the lethal triad to the lethal diamond? J Trauma Acute Care Surg. 2020;88:434-9. Doi: 10.1097/TA.0000000000002570

21. Ordoñez CA, Rodríguez F, Orlas CP, Parra MW, Caicedo Y, Guzmán M, et al. The critical threshold value of systolic blood pressure for aortic occlusion in trauma patients in profound hemorrhagic shock. J Trauma Acute Care Surg. 2020;89:1107-13. Doi: 10.1097/TA.0000000000002935.

22. Ordoñez CA, Rodríguez F, Parra M, Herrera JP, Guzmán-Rodríguez M, Orlas C, et al. Resuscitative endovascular balloon of the aorta is feasible in penetrating chest trauma with major hemorrhage: Proposal of a new institutional deployment algorithm. J Trauma Acute Care Surg. 2020;89:311-9. Doi: 10.1097/ ta.0000000000002773.

23. García AF, Manzano-Nunez R, Orlas CP, Ruiz-Yucuma J, Londoño A, Salazar C, et al. Association of resuscitative endovascular balloon occlusion of the aorta (REBOA) and mortality in penetrating trauma patients. Eur $\mathrm{J}$ Trauma Emerg Surg. 2020:10.1007/s00068-020-01370-9. Doi: 10.1007/s00068-020-01370-9.

24. Burlew CC, Moore EE, Moore FA, Coimbra R, McIntyre RC, Davis JW, et al. Western trauma association critical decisions in trauma: Resuscitative thoracotomy. J Trauma Acute Care Surg. 2012;73:1359-63. Doi: 10.1097/TA.0b013e318270d2df.

25. Garcia AF, Manzano-Nunez R, Bayona JG, Millan M, Puyana JC. A clinical series of packing the wound tract for arresting traumatic hemorrhage from injuries of the lung parenchyma as a feasible damage control technique. World J Emerg Surg. 2019;14:52. Doi: 10.1186/s13017-019-0273-y.

26. Moriwaki Y, Toyoda H, Harunari N, Iwashita M, Kosuge T, Arata S, et al. Gauze packing as damage control for uncontrollable haemorrhage in severe thoracic trauma. Ann R Coll Surg Engl. 2013;95:20-5. Doi: 10.1308/00 $3588413 \times 13511609956057$. 
27. Mackowski MJ, Barnett RE, Harbrecht BG, Miller KR, Franklin GA, Smith JW, et al. Damage control for thoracic trauma. Am Surg. 2014;80:910-3.

28. Wall J, Soltero E. Damage control for thoracic injuries. Surg Clin North Am. 1997;77:863-78. Doi: 10.1016/ S0039-6109(05)70590-9.

29. Asensio JA, Petrone P, Kimbrell B, Kuncir E. Toracotomía de emergencia. Evaluación crítica de la técnica. Rev Colomb Cirugía. 2006;21:75-86.

30. Velmahos GC, Baker C, Demetriades D, Goodman J, Murray JA, Asensio JA. Lung-sparing surgery after penetrating trauma using tractotomy, partial lobectomy, and pneumonorrhaphy. Arch Surg. 1999;134:186-9. Doi: 10.1001/archsurg.134.2.186.

31. Huh J, Wall MJ, Estrera AL, Soltero ER, Mattox KL. Surgical management of traumatic pulmonary injury. Am J Surg. 2003;186:620-4. Doi: 10.1016/j.amjsurg.2003.08.013.

32. Wall MJ, Hirshberg A, Mattox KL. Pulmonary tractotomy with selective vascular ligation for penetrating injuries to the lung. Am J Surg. 1994;168:665-9. Doi: 10.1016/S0002-9610(05)80141-2.

33. Asensio JA, Demetriades D, Berne JD, Velmahos G, Cornwell EE, Murray J, et al. Stapled pulmonary tractotomy: A rapid way to control hemorrhage in penetrating pulmonary injuries. J Am Coll Surg. 1997;185:486-7. Doi: 10.1016/S1072-7515(97)00070-7.

34. Phillips B, Turco L, Mirzaie M, Fernandez C. Trauma pneumonectomy: A narrative review. Int J Surg. 2017;46:71-4. Doi: 10.1016/j.jijsu.2017.08.570.

35. Asensio JA, Ogun OA, Mazzini FN, Perez-Alonso AJ, Garcia-Núñez LM, Petrone P. Predictors of outcome in 101 patients requiring emergent thoracotomy for penetrating pulmonary injuries. Eur J Trauma Emerg Surg. 2018;44:55-61. Doi: 10.1007/s00068-017-0802-x.

36. Karmy-Jones R, Jurkovich GJ, Shatz D V., Brundage S, Wall MJ, Engelhardt S, et al. Management of traumatic lung injury : a western trauma association multicenter review. J Trauma. 2001;51:1049-53. Doi: 10.1097/00005373-200112000-00004.

37. Lang JL, Gonzalez RP, Aldy KN, Carroll EA, Eastman AL, White CQ, et al. Does temporary chest wall closure with or without chest packing improve survival for trauma patients in shock after emergent thoracotomy? J Trauma. 2011;70:705-9. Doi: 10.1097/TA.0b013e31820e89f1.

38. Glaser JJ, Neidert LE, Morgan CG, Brenner M, Stigall KS, Cardin S. Resuscitative Endovascular Balloon Occlusion of the Aorta (REBOA) for Thoracic Trauma: A Translational Swine Study. J Trauma Acute Care Surg. 2020; 89(3):474-481. Doi: 10.1097/TA.0000000000002749.

39. Garcia AF, Vargas M, Aldana J. Respiratory physiology in damage control thoracotomy and intra-thoracic packing after severe penetrating chest trauma (Personnal Communication). 2020. 